\title{
Broker-Dealer Competition in the Korean Financial Securities Markets*
}

\author{
Jae-Hyun Gwon**
}

Received: March 15, 2018. Revised: March 30, 2018. Accepted: April 15, 2018.

\section{Abstract}

Purpose - This study measures how competitive securities broker-dealers are in the Korean financial markets. It aims to test whether the markets are perfectly competitive or monopolistic since the global financial crisis of 2008.

Research design, data, and methodology - We apply the method developed by Panzar and Rosse (1987), H-statistics, which offers an index for the competitiveness as well as statistical tests. The dataset in use is retrieved mainly from the quarterly statements of the financial services companies by the Financial Statistics Information System of the Financial Supervisory Service. General information on officers and employees is utilized in addition to balance sheets and income statements of securities companies.

Results - H-statistics for $2009-2015$ is about 0.7 that is a robust estimate regardless of model specifications such as full trans-log, partial trans-log, and Cobb-Douglas regression equations. H-statistics for each year is also computed in similar ways in that it varies between 0.3 and 0.9 .

Conclusions - Since the global financial crisis, $\mathrm{H}$-statistics concludes that securities broker-dealer markets in Korea is neither perfectly competitive nor monopolistic. It evidences that the markets are rather monopolistically competitive. The trend in annual $\mathrm{H}$-statistics leads to the same conclusion but the result is not such stable that overall $\mathrm{H}$-statistics implies.

Keywords: H-statistics, Panzar-Rosse Models, Competition, Securities Broker-Dealer.

JEL Classifications: D4, G24, L22.

\section{Introduction}

This paper examines how the competition in the Korean financial securities markets has evolved from year 2009 to 2016. The degree of competition among the securities broker-dealers has been a high concern for themselves as well as for the regulator. While securities intermediaries are reluctant to accommodate intensified competition, the regulator would like to promote proper competition to maximize social or consumer's welfare unless it does not harm the overall stability of financial system. Financial customers or individual investors would prefer fierce competition between the securities firms since it likely brings about lower service fees.

Compared to the literature of banking, we are not sure of the optimal competitiveness among the financial securities

* This work was supported by Incheon National University Research Grant in 2016.

** First Author, School of Northeast Asian Studies, Incheon National University, Korea. Tel: +82-32-835-8722, E-mail: gwon@inu.ac.kr firms: Fiercer competition is expected to benefit financial consumers. Yet it might drive the securities firms on the brink of bankruptcy, hence higher odds of the system risk might be stacked on the entire financial markets.

Absent theoretical analysis or empirical examination, it is frequently said that the market competition in Korea has risen to the extent that additional entry cannot be accommodated by the incumbents. Contrary to the market saturation argument, the securities investment companies are not willing to exit while voluntary mergers or takeovers between the companies are rare (Gwon \& Park, 2016). That is why the market saturation story is doubted. In this aspect, the precise measurement of the securities markets competition must precede normative arguments or any regulatory policies.

We apply a methodology from new empirical industrial organization to meter securities broker-dealer industry in Korea. Many, if not most, empirical research usually draws on the traditional methods such as Hirfindahl-Hirschman index $(\mathrm{HHI})$ or concentration ratio $(\mathrm{CR})$. They are, however, well known to have some critical drawbacks. Above all, those measures are computed by the consequential 
outcomes that might be confounded with other factors except for competition. For example, a market leader with cost-saving efficiency and/or better business tactics is likely to end up with a dominant market share, which would result in high $\mathrm{HHI}$ and $\mathrm{CR}$. Despite the fierce competition, the resultant measures, high $\mathrm{HHI}$ and $\mathrm{CR}$, falsely appear to indicate that the industry is in the status of monopoly.

To overcome the shortcoming of frequently used measures, we would like to take another approach by Panzar and Rosse (1987). One of the advantages of this alternative method is that we can derive testable implications adding structural modeling assumptions on firm's production function. The structural models comprise the set of intuitive assumptions and they enable us to obtain reduced-form regressions for estimation or test, that is, $\mathrm{H}$-statistics. Section 2 provides a broad review of the related literature with special attention on finance.

Section 3 explains the methodology including dataset description and regression specifications in detail. Provided are full description of variables and their descriptive statistics.

In Section 4, various $\mathrm{H}$-statistics by Panzar and Rosse (1987) based on section 3 are reported. Followed are further remarks and conclusions in section 5 .

\section{Literature Review}

\subsection{Traditional Measures and Their Limits}

Traditional industrial organization follows a research agenda by Bain (1956). Market structure impacts on individual firm's conduct that decides the societal performance, so called SCP (Structure-Conduct-Performance). In modern terminology, "structure" stands for the mode of competition, "conduct" for firm's behavior, and "performance" for social efficiency. Until the decline of SCP paradigm in the 1990s, HHI or CR had been the most popular measures for "structure" (Degryse, Kim, \& Ongena, 2009).

Both $\mathrm{HHI}$ and $\mathrm{CR}$ are easy to compute because they are based on the observed market shares. $\mathrm{HHI}$ is the sum of the squared market shares and CR is simply the sum of market leaders' shares. It must be noticed that these measures likely fail to grasp true contestability. In equilibrium, there will be no change in market shares even if the market is close to perfect competition. Provided that a potential entrant anticipating no gain would stay out of the market, there would be no exit or entry in equilibrium, other things being equal (Baumol, Panzar, \& Willig, 1982). Another simple example is a Bertrand duopoly model of price competition. The equilibrium outcome is that two firms with the same marginal cost would charge the same price, thus, they make no profit while having the customers equally by half and half. In this case, $\mathrm{HHI}(=50,000)$ is quite high but the firms feel cut-throat competition with no profit According to the horizontal merger guideline $\S 5.2$ by U.S.
Department of Justice and the Federal Trade Commission (2010), the market with $\mathrm{HHI}$ lower than 1,500 is determined to be "unconcentrated." If $\mathrm{HHI}$ is greater than 2,500 , it is defined to be "highly concentrated." Otherwise, the market is considered "moderately concentrated." Observed competition measure might differ from real contestability.

\subsection{H-statistics by Panzar and Rosse (1987)}

New approaches are developed to get the better of these drawbacks with traditional concentration measures. One of the successful alternatives is $\mathrm{H}$-statistics by Panzar and Rosse (1987). Many contemporary researches relating to the financial regulations compute $\mathrm{H}$-statistics for financial markets, especially banking sector. Popular use of $\mathrm{H}$-statistics tends to enable international comparison of and time serial change in banking competition (Classens \& Laeven, 2004; Bikker \& Spierdijk, 2008).

$\mathrm{H}$-statistics draws empirically on the accounting statements of individual firms. Different mode of competition brings about a distinct relationship between the change in revenue and the change in input prices. Depending on this result, Panzar and Rosse (1987) suggest a test to determine whether a market is monopolistic or not. As such, they provide a similar test to decide whether it is close to perfect competition. The basic idea is that the change in revenue to the factor prices depends on the market structure.

Suppose, for example, that a firm be the sole monopolist. Absent regulation, it would maximize the profit where the marginal cost equalizes the marginal revenue. In equilibrium, the price elasticity of demand is greater than or equal to the unity. Therefore, when the prices of input factors rise proportionately, the revenue will decline with the rise in price. Implied is that the revenue moves in the opposite direction of the input prices if a market is structured in monopolistic way.

On the other extreme, we suppose that a firm operate in a perfectly competitive market. The equilibrium price equals the marginal cost where an individual firm's revenue should increase at the same rate of the factor price increase. In a perfectly competitive market, there is no way to make a profit but to increase the revenue enough to cover the higher cost.

In sum, the above implications are structured by regression equation(1). For individual firm $i$ at time $t$, revenue $R$ is a function of input factor $f$ 's price $p$, other control variables $x$, and error term $\epsilon$ that is unobservable to econometricians.

$$
\ln \left(R_{i t}\right)=\alpha+\Sigma_{f} \beta_{f} \ln \left(p_{f, i t}\right)+\gamma^{\prime} x_{i t}+\epsilon_{i t}
$$

Conventionally, the revenue and input factor prices are configured in terms of percentage. It is why the revenue and the factor prices are in logarithmic form. Other variables are 
lumped into the vector of control variables, $x_{i t}$, where the variables might be or might not be dependent of individual firm index $i$ and time $t$. Vector $x_{i t}$ may include interaction terms of logarithmic factor prices as well as other exogenous variables. Error term $\epsilon_{i t}$ 's are assumed to be independent and identically distributed and they follow normal distribution with mean zero.

Now $\mathrm{H}$-statistics is defined by the sum of factor price elasticities of revenue such that

$$
H \equiv \Sigma_{f} \beta_{f}
$$

$H \leq 0$ holds for the monopoly and $H=1$ for the perfect competition. Otherwise, for $0<H<1$, we would state that monopolistic competition - Panzar and Rosse (1987) use the terminology of Chamberlinian model where the firms merit some monopolistic rent by product differentiation - is in place. Based on the theoretical model, $\mathrm{H}$-statistics offers testable hypotheses to determine the degree of competition. As the $\mathrm{H}$-statistics increases from 0 to 1 , we can claim that the market tends to a perfect competition from a monopoly.

There are technical remarks to add. H-statistics draws on an equilibrium model. Time span in which we calculate the statistics matters since it would not be guaranteed that the market is in equilibrium for narrowly defined time (Nathan \& Neave, 1989; Claessens \& Laeven, 2004). It would be also noted that $\mathrm{H}$-statistics changes sensitively when we construct numerous grids for a given period of time (De Bandt \& Davis, 2000; Bikker \& Spierdijk, 2008).

\subsection{Some Applications to Financial Markets}

Pertaining to financial markets, especially banking, there are numerous papers on $\mathrm{H}$-statistics so that they receive comprehensive survey on this literature (Bikker \& Haaf, 2002; Classens, 2009). Most literature is to probe the banking competition in the advanced economy such as Europe and North America. But it goes beyond the developed region (Humairoh \& Usman, 2016), and some papers attain international comparison by the same standards (Classens \& Laeven, 2004; Bikker \& Spierdijk, 2008).

Classens and Laeven (2004) compile banking data in 50 countries from 1994 to 2001 to compute H-statistics. Most countries record $\mathrm{H}$-statistics in the range of 0.50 and 0.85 , which states that they are in monopolistic competition. In addition, they investigate the relation between $\mathrm{H}$-statistics and regulation policies to conclude that strong regulation is correlated with low $\mathrm{H}$-statistics. It hints that $\mathrm{H}$-statistics might be a good measure for contestability. Similarly, Bikker and Spierdijk (2008) extend $\mathrm{H}$-statistics of banking sector into 101 countries over 1989-2004. Their study is comprehensive, and it finds that $\mathrm{H}$-statistics differ from Classens and Laeven (2004) for some countries.

Regarding financial securities broker-dealer market, $\mathrm{H}$-statistics has received scant attention. To my best knowledge, Tsutsui and Kamesaka (2005) is the most comparable study to abundant banking literature. Applying De Bandt and Davis (2000) into Japanese securities industry, they conclude that the market is far from perfect competition even in the wake of consecutive liberalization of regulations.

This paper applies the basic methodology by Tsutsui and Kamesaka (2005) into Korean financial investment industry with more detailed accounting information. Japan and Korea are under similar legal and regulatory system that enforce a strict division of commercial banking and investment banking. Since the similarity of securities broker-dealer business in both countries, one of the purpose of this paper is to establish comparable analysis to Tsutsui and Kamesaka (2005). At the same time, this paper is to re-examine and extend the previous literature that probe the degree of financial investment industry in Korea (Lee, Shin, Lee, \& Park, 2008; Gwon \& Park, 2016).

\section{Model and Analysis}

\subsection{Dataset}

We focus on the computation of $\mathrm{H}$-statistics regarding financial securities trading in Korea. All the financial services firms encompassing commercial banks, insurers, investment firms, non-bank financial companies must report their financial statements to the Financial Supervisory Service (FSS) by the Financial Investment Services and Capital Markets Act (FISCMA). These financial reports offer specific information about financing and key management indices of financial services companies.

There are two versions of the financial statements: Reported statements to the regulator and the summarized ones to the public. Summarized version of the statements is publicized by the Financial Statistics Information System (FISIS) after the FSS scrutinized them. Originally reported statements contain more detailed transactions, and they are retained in the FSS. The detailed original statements are provided to the researchers at request, which are partially used in this paper since the public data lack of detailed accounting items fail to classify profit sources by types of business. Thanks to this detail of the reported statements, we can arrange the revenue and the cost by business portfolios.

The financial statements are reported quarterly to the FSS unless the securities companies are out of business. Among quarterly statements, we use balance sheets for stock variables such as asset, liability, and equity. Income statements are useful for flow variables. Added are workforce data such as number of employees, directors, and outside auditors.

The scope of data entails the securities companies with broker-dealer licenses granted by the Financial Investment 
Services and Capital Markets Act. From March 2002 to December 2016, quarterly financial statements are collected. Using specific details, we can arrange the revenue and the cost by business portfolios - brokerage, investment banking, asset management, and dealing on its own account. Among quarterly financial statements, we use balance sheets for stock variables such as asset, liability, and equity. Profit/loss statements are useful for flow variables. Added are workforce information such as the number of rank-and-file employees, directors and executives, and outside auditors.

There are some accounting issues to remark. The fiscal year of the securities companies had been ending at May until fiscal year 2013. By the FISCMA, since May 31, 2013, the companies are allowed change their fiscal year to end at December. Except for a few firms, most of companies did change their fiscal ending to December. Therefore, we need to be careful that there are only three quarters for FY 2013. This problem requires careful attention on income statements. Quarterly income statements are usually recorded in cumulative fashion, so we need to take a difference between two consecutive income statements to calculate the quarterly performance purely confined to the corresponding quarter

The most serious problem resides in the consistency of accounting rules. There have been some major and minor changes in accounting principles. Among them, the change in June 2009 was substantial that some accounting items are disconnected at this moment. Before the introduction of the International Financial Reporting Standards (IFRS) in 2011, some major changes in balance sheet items were already admitted: Classification of liabilities was changed from June 2007 and further change was followed at June 2009.

The entire collection of raw data starts from March 2002. Be that as it may, we should drop the data observations earlier than June 2009 for accounting consistency. Otherwise, the reliability of $\mathrm{H}$-statistics is hard to be warranted, and the change in competition over time would lose the credibility. The truncated dataset used in this paper begins from September 2009 in effect, which commences in the aftermath of the global financial crisis. One needs to remark is that there are only two quarters in 2009 and complete four quarters thereafter.

The beginning of the dataset coincides with the periods after the global financial crisis. Aside from the accounting problem, Korean stock market is considered to experience a change (Sohn \& Liu, 2015). In this sense, it would be justified that we confine our analysis to the time since the global financial crisis.

\subsection{Regression Specifications and Variables}

In general, H-statistics are formed on equation (1). For each firm-year, we have four different quarterly data observations. As noted, 2009 has only two quarterly observations. The regression specification for $\mathrm{H}$-statistic follows Tsutsui and Kamesaka (2005):

$$
\ln \left(R_{i t}\right)=\alpha+\beta_{w} \ln w_{i t}+\beta_{r} \ln r_{i t}+\beta_{k} \ln k_{i t}+\gamma^{\prime} x_{i t}+\epsilon_{i t}
$$

where the dependent variable, $R$, is the operating revenue, and major input factor prices are defined by the wage rate $(w)$, financial cost $(h)$, and capital equipment cost $(k)$.

Wage rate is denoted by the average compensation on workers, that is,

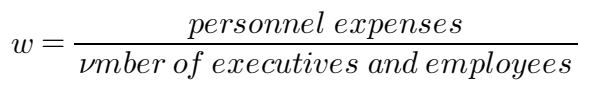

where personnel expenses are the sum of salary, severance pay, payment for early retirement, and other benefits for employees. The number of executive and employees are total number of rank-and-file employees, directors and executives, and outside auditors. Financial cost is represented by

$$
r=\frac{\text { financial costs }}{\text { financial borrowings }}
$$

where financial costs are simply taken from interest expense, and financial borrowings are the sum of deposits and borrowings. Rental cost on capital equipment is defined by

$$
k=\frac{\text { expenses on assets }}{\text { tangible fixed assets }}
$$

where expenses on assets include rental expenses, depreciation, vehicles maintenance expenses, supplies expenses, and utility expenses. The value of tangible fixed assets is taken from the accounting item in the balance sheets each quarter.

Dependent variable, $\mathrm{R}$, and three independent variables, $(w, r, k)$ are logarithmic values. Following Tsutsui and Kamesaka (2005), we use the residual value after subtracting the mean of each log variable in each year, that is, $\ln \left(p_{f, i t}\right)-E_{t}\left(\ln p_{f, i t}\right)$ for any year $t$.

To control for firm specific characteristics, we add other exogenous variables such as BROKERIASSET, IBIASSET, AMASSET, DEALIASSET, In(ASSET), dummy variables for quarters and dummy variables for whether the company is domestically incorporated or not. Variable BROKER represents quarterly net income from brokerage services, $I B$ stands for net income from investment banking service, $A M$ for asset management, $D E A L$ for dealing in its own interest, and ASSET for total asset. Here all the net incomes by business portfolio are classified and computed by the Korea Capital Market Institute based on the same dataset.

$<$ Table 1> displays the mean values of key variables mentioned above in each year. 
<Table 1> Summary statistics of key variables for FY 2009-2016

\begin{tabular}{|c|c|c|c|c|c|c|c|c|}
\hline Year & $\boldsymbol{R}$ & $\boldsymbol{w}$ & $\boldsymbol{r}$ & $\boldsymbol{k}$ & $\frac{\text { BROKER }}{A S S E T}$ & $\frac{I B}{A S S E T}$ & $\frac{A M}{A S S E T}$ & $\frac{D E A L}{A S S E T}$ \\
\hline 2009 & $1,767.96$ & 0.396 & 0.033 & 0.246 & 0.020 & 0.002 & 0.001 & 0.007 \\
\hline 2010 & $2,309.58$ & 0.410 & 0.048 & 0.292 & 0.021 & 0.002 & 0.001 & 0.008 \\
\hline 2011 & $2,689.95$ & 0.396 & 0.019 & 0.361 & 0.017 & 0.002 & 0.001 & 0.006 \\
\hline 2012 & $1,878.44$ & 0.405 & 0.035 & 0.373 & 0.012 & 0.002 & 0.001 & 0.004 \\
\hline 2013 & $1,813.66$ & 0.414 & 0.022 & 0.465 & 0.011 & 0.002 & 0.001 & -0.005 \\
\hline 2014 & $1,904.72$ & 0.415 & 0.345 & 0.587 & 0.015 & 0.002 & 0.000 & 0.005 \\
\hline 2015 & $2,735.95$ & 0.452 & 0.163 & 0.478 & 0.009 & 0.002 & 0.001 & 0.004 \\
\hline 2016 & $3,045.46$ & 0.485 & 0.129 & 0.499 & 0.008 & 0.004 & 0.001 & 0.002 \\
\hline Total & $3,265.15$ & 0.472 & 0.614 & 0.435 & 0.008 & 0.004 & 0.001 & 0.004 \\
\hline
\end{tabular}

Note 1: Operating revenue is denominated by KRW 100,000,000.

Note 2: Input factor costs $(w, r, k)$ are dropped as outliers if the rates are missing, greater than 100 , or less than 0.

Note 3: Total is the overall average over the periods in which the data are available. Financial costs are available from 2007 and capital costs are available from 2009. All other variables are available from 2002.

As described in section 3.1, complete set of variables begins at September 2009. However, we can compute all the variables since June 2002 except for financial cost, $r$, and rental rate on facilities, $k$. The last row of <Table $1>$ shows the average of all the available observations since FY 2002.

Average operating revenue tends to grow but it had declined for 2012 and 2013. It is on the rise recently. Average compensation on a worker, $w$, is about KRW $38,700,000$ per year and it gradually increases up to KRW $48,000,000$ now. Financial cost, $r$, is around $12 \%$ on average but it fluctuates widely between $2 \%$ and $61 \%$. Rental rate, $k$, on physical facilities is $42 \%$ on average, which includes depreciation. Capital cost, $k$, is continuously rising from $25 \%$ to $50 \%$. When it comes to the business portfolio, brokerage share in terms of total asset is falling. Asset management service does not seem to generate significant profit and the investment banking service has been stagnant except for 2016. Securities dealing business becomes a large profit source rather than other traditional services, but its performance is so risky to be volatile by the nature of the business. In 2013 , for instance, the securities companies lost the profit from dealing business.

Now we consider three distinct specifications for the regression of $\mathrm{H}$-statistics: Full trans-log, partial trans-log, and Cobb-Douglas function. Equation (2) is of the Cobb-Douglas function, whereas the partial trans-log function adds the squared $(\ln w, \ln r, \ln k)$ into the right-hand-side of equation (2), and the full trans-log function additionally appends all possible cross-terms between $(\ln w, \ln r, \ln k)$ onto the partial trans-log function. Equation (3) and (4) represent full and partial trans-log regression functions, respectively:

$$
\begin{aligned}
\ln \left(R_{i t}\right)= & \alpha+\beta_{w} \ln w_{i t}+\beta_{r} \ln r_{i t}+\beta_{k} \ln k_{i t}+\gamma^{\prime} x_{i t}+\delta_{1}\left(\ln w_{i t}\right)^{2} \\
& +\delta_{2}\left(\ln r_{i t}\right)^{2}+\delta_{3}\left(\ln k_{i t}\right)^{2}+\kappa_{1} \ln w_{i t} \times \ln r_{i t} \\
& +\kappa_{2} \ln w_{i t} \times \ln k_{i t}+\kappa_{3} \ln r_{i t} \times \operatorname{In} k_{i t}+\epsilon_{i t}
\end{aligned}
$$

$$
\begin{aligned}
\ln \left(R_{i t}\right)= & \alpha+\beta_{w} \ln w_{i t}+\beta_{r} \ln r_{i t}+\beta_{k} \ln k_{i t}+\gamma^{\prime} x_{i t} \\
& +\delta_{1}\left(\ln w_{i t}\right)^{2}+\delta_{2}\left(\ln r_{i t}\right)^{2}+\delta_{3}\left(\ln k_{i t}\right)^{2}+\epsilon_{i t}
\end{aligned}
$$

Theory is hardly able to decide which specification fits the best a priori that we would test them empirically. Full trans-log specification (3) is the unrestricted model. Against it, the partial trans-log specification (4) restricts coefficients such that $\kappa_{1}=\kappa_{2}=\kappa_{3}=0$. Similarly, the Cobb-Douglas model (2) restricts the coefficients such that $\delta_{1}=\delta_{2}=\delta_{3}=\kappa_{1}=\kappa_{2}=\kappa_{3}=0$.

<Table 2> F-tests for partial trans-log and Cobb-Douglas function for FY 2009-2016

\begin{tabular}{|l|c|c|}
\hline Tests & F-statistics & p-value \\
\hline H0: Cobb-Douglas vs H1: Partial trans-log & 6.15 & 0.0004 \\
\hline H0: Cobb-Douglas vs H1: Full trans-log & 7.97 & 0.0000 \\
\hline H0: Partial trans-log vs H1: Full trans-log & 9.70 & 0.0000 \\
\hline
\end{tabular}

<Table 2> displays the F-test results on three different specifications. Using full samples from 2009 to 2016, we test the validity of the restricted models, Cobb-Douglas and partial trans-log specifications, to conclude that the partial trans-log and the Cobb-Douglas models are rejected at any significance level. Thus, the full trans-log model will be of major concern for estimation and test from now on.

\section{Results}

In this section, we report estimations for the overall estimation for H-statistics from September 2009 to December 2016. Estimates of the models with full and partial trans-log functions as well as Cobb-Douglas one are summarized in $<$ Table 3>. 
<Table 3> H-statistics with full trans-log, partial trans-log, and Cobb-Douglas model specifications for FY 2009-2016

\begin{tabular}{|c|c|c|c|c|c|c|}
\hline $\begin{array}{l}\text { Dependent } \\
\text { variable }\end{array}$ & \multicolumn{2}{|c|}{ Full trans-log } & \multicolumn{2}{|c|}{ Partial trans-log } & \multicolumn{2}{|c|}{ Cobb-Douglas } \\
\hline $\ln$ (revenue) & coefficient & $p$-value & coefficien & $p$-value & coefficien & $\mathrm{p}$-value \\
\hline $\ln (w)$ & 0.603 & 0.000 & 0.618 & 0.000 & 0.587 & 0.000 \\
\hline $\ln (r)$ & 0.194 & 0.000 & 0.120 & 0.000 & 0.077 & 0.000 \\
\hline $\ln (k)$ & -0.028 & 0.148 & -0.035 & 0.070 & -0.034 & 0.069 \\
\hline BROKERIASSET & 5.182 & 0.000 & 5.102 & 0.000 & 5.155 & 0.000 \\
\hline IB/ASSET & 6.288 & 0.023 & 7.064 & 0.011 & 6.143 & 0.027 \\
\hline AM/ASSET & 55.379 & 0.000 & 55.201 & 0.000 & 55.721 & 0.000 \\
\hline \begin{tabular}{|l|} 
DEAL/ASSET \\
\end{tabular} & 0.086 & 0.802 & 0.274 & 0.423 & 0.306 & 0.371 \\
\hline In(asset) & 0.967 & 0.000 & 0.973 & 0.000 & 0.978 & 0.000 \\
\hline$(\ln (w))^{2}$ & -0.059 & \begin{tabular}{|l|}
0.354 \\
\end{tabular} & 0.041 & 0.461 & - & - \\
\hline$(\ln (r))^{2}$ & -0.011 & 0.002 & -0.014 & 0.000 & - & - \\
\hline$(\ln (k))^{2}$ & -0.010 & 0.452 & -0.006 & 0.605 & - & - \\
\hline $\ln (w)^{*} \ln (r)$ & -0.068 & 0.022 & - & - & - & - \\
\hline $\ln (w)^{*} \ln (k)$ & 0.059 & 0.132 & - & - & - & - \\
\hline $\ln (\mathrm{r})^{\star} \ln (\mathrm{k})$ & -0.079 & 0.000 & - & - & - & - \\
\hline $\mathrm{H}$-statistics & \multicolumn{2}{|c|}{0.768} & \multicolumn{2}{|c|}{0.702} & \multicolumn{2}{|c|}{0.630} \\
\hline \begin{tabular}{|l|} 
Adjusted $\mathrm{R}^{2}$ \\
\end{tabular} & \multicolumn{2}{|c|}{0.837} & \multicolumn{2}{|c|}{0.835} & \multicolumn{2}{|c|}{0.834} \\
\hline \begin{tabular}{|c|}
$\begin{array}{c}\text { No. of } \\
\text { observations }\end{array}$ \\
\end{tabular} & \multicolumn{2}{|c|}{1,886} & \multicolumn{2}{|c|}{1,886} & \multicolumn{2}{|c|}{1,886} \\
\hline $\mathrm{p}(\mathrm{H}=0)$ & \multicolumn{2}{|c|}{0.000} & \multicolumn{2}{|c|}{0.000} & \multicolumn{2}{|c|}{0.000} \\
\hline $\mathrm{p}(\mathrm{H}=1)$ & \multicolumn{2}{|c|}{0.000} & \multicolumn{2}{|c|}{0.000} & \multicolumn{2}{|c|}{0.000} \\
\hline
\end{tabular}

Note: Estimates for dummy variables are suppressed.

Changes in labor cost, $w$, and financial cost, $r$, are significantly related to the change in revenue. However, cost of physical facilities, $k$, does not have a significant effect on the revenue and its sign is negative in contrast to common sense.

Out of business lines, the shares of brokerage service, investment banking, and asset management do have significantly positive impact on the revenue. Earning from dealing securities is positively related to the change in revenue but the effect is not significantly different from zero.

The size of each company, proxied by the logarithmic total asset, $\ln$ (asset), does have a significantly positive influence on the revenue. Here all the coefficient estimates for dummy variables are suppressed. For all specifications, one can remark that whether a firm is incorporated in Korea is significant while quarter dummies are not.

Given estimates, we compute H-statistics. Even if the statistics are different across the specifications, we can conclude that $\mathrm{H}$-statistics are around 0.7 . The null hypothesis of "monopoly" or "perfect competition" are rejected (bottom) so that we would maintain broker-dealers market in Korea has been in "monopolistic competition" since the global financial crisis around 2008. It is a robust result which does not depend much on model specifications.

Dividing the entire time span into each year, we reiterate the computation to meter how the degree of the competition changes. <Table $4>$ reports the annual $\mathrm{H}$-statistics with full trans-log functions over time. Note that there are only two quarters for 2009.
<Table 4> Annual $\mathrm{H}$-statistics of securities broker-dealer markets in Korea for FY 2009-2016

\begin{tabular}{|c|c|c|c|c|c|c|c|c|}
\hline \multicolumn{9}{|c|}{ Dependent variable $=\ln ($ revenue $)$} \\
\hline \multirow[t]{2}{*}{ Fiscal year } & \multicolumn{2}{|c|}{2009} & \multicolumn{2}{|c|}{2010} & \multicolumn{2}{|c|}{2011} & \multicolumn{2}{|c|}{2012} \\
\hline & Coeff. & p-val & Coeff. & $p$-val & Coeff. & p-val & Coeff. & p-val \\
\hline $\ln (w)$ & 0.23 & 0.21 & 0.47 & 0.00 & 0.42 & 0.02 & 0.62 & 0.00 \\
\hline $\ln (r)$ & -0.03 & 0.67 & 0.12 & 0.15 & 0.06 & 0.49 & 0.05 & 0.53 \\
\hline $\ln (k)$ & 0.09 & 0.34 & 0.10 & 0.18 & 0.00 & 0.99 & -0.01 & 0.86 \\
\hline BROKER/ASSET & 18.43 & 0.00 & 13.75 & 0.00 & 7.30 & 0.03 & 20.46 & 0.00 \\
\hline IB/ASSET & 3.55 & 0.78 & $-21.70 \mid$ & 0.13 & $\mid 14.79$ & 0.14 & $\mid-1.72$ & 0.91 \\
\hline AM/ASSET & 33.61 & 0.28 & 9.16 & 0.72 & -15.28 & 0.65 & 3.59 & 0.87 \\
\hline DEAL/ASSET & 35.84 & 0.00 & 34.24 & 0.00 & 38.29 & 0.00 & 57.21 & 0.00 \\
\hline In(asset) & 1.18 & 0.00 & 1.12 & 0.00 & 1.11 & 0.00 & 1.09 & 0.00 \\
\hline$(\ln (w))^{2}$ & 0.22 & 0.20 & 0.14 & 0.47 & 0.49 & 0.03 & 0.13 & 0.40 \\
\hline$(\ln (r))^{2}$ & 0.01 & 0.56 & -0.01 & 0.23 & -0.02 & 0.17 & -0.03 & 0.10 \\
\hline$(\ln (k))^{2}$ & 0.03 & 0.55 & 0.01 & 0.89 & 0.01 & 0.85 & -0.03 & 0.46 \\
\hline $\ln (w)^{*} \ln (r)$ & 0.18 & 0.21 & -0.14 & 0.16 & -0.19 & 0.17 & -0.09 & 0.44 \\
\hline $\ln (w)^{*} \ln (k)$ & 0.05 & 0.74 & 0.09 & 0.46 & -0.31 & 0.03 & -0.18 & 0.12 \\
\hline $\ln (r)^{\star} \ln (k)$ & -0.09 & 0.27 & -0.06 & 0.44 & 0.04 & 0.56 & 0.08 & 0.27 \\
\hline H-statistics & \multicolumn{2}{|c|}{0.28} & \multicolumn{2}{|c|}{0.69} & \multicolumn{2}{|c|}{0.47} & \multicolumn{2}{|c|}{0.66} \\
\hline Adjusted $\mathrm{R}^{2}$ & \multicolumn{2}{|c|}{0.86} & \multicolumn{2}{|c|}{0.87} & \multicolumn{2}{|c|}{0.84} & \multicolumn{2}{|c|}{0.89} \\
\hline No. of obs. & \multicolumn{2}{|c|}{175} & \multicolumn{2}{|c|}{239} & \multicolumn{2}{|c|}{237} & \multicolumn{2}{|c|}{238} \\
\hline $\mathrm{p}(\mathrm{H}=0)$ & \multicolumn{2}{|c|}{0.23} & \multicolumn{2}{|c|}{0.00} & \multicolumn{2}{|c|}{0.02} & \multicolumn{2}{|c|}{0.00} \\
\hline$p(H=1)$ & \multicolumn{2}{|c|}{0.00} & \multicolumn{2}{|c|}{0.13} & \multicolumn{2}{|c|}{0.01} & \multicolumn{2}{|c|}{0.02} \\
\hline
\end{tabular}

\begin{tabular}{|c|c|c|c|c|c|c|c|c|}
\hline \multicolumn{9}{|c|}{ Dependent variable $=\ln ($ revenue $)$} \\
\hline \multirow[t]{2}{*}{ Fiscal year } & \multicolumn{2}{|c|}{2013} & \multicolumn{2}{|c|}{2014} & \multicolumn{2}{|c|}{2015} & \multicolumn{2}{|c|}{2016} \\
\hline & Coeff. & p-val & Coeff. & p-val| & Coeff. & $\mathrm{p}$-val & Coeff. & p-val \\
\hline $\ln (w)$ & 0.46 & 0.00 & 0.65 & 0.00 & 0.49 & 0.00 & 0.76 & 0.00 \\
\hline $\ln (r)$ & 0.05 & 0.45 & 0.21 & 0.00 & 0.10 & 0.16 & 0.20 & 0.00 \\
\hline $\ln (k)$ & 0.04 & 0.34 & 0.05 & 0.22 & -0.14 & 0.00 & -0.14 & 0.01 \\
\hline BROKER/ASSET & 13.68 & 0.00 & 1.93 & 0.00 & 17.86 & 0.01 & 13.28 & 0.06 \\
\hline IB/ASSET & 28.88 & 0.03 & 14.58 & 0.16 & -8.57 & 0.28 & 6.96 & 0.09 \\
\hline AM/ASSET & 34.73 & 0.14 & 296.83 & 0.00 & 62.88 & 0.38 & 60.29 & 0.23 \\
\hline DEAL/ASSET & -0.31 & 0.57 & 16.30 & 0.00 & 43.59 & 0.00 & 10.29 & 0.31 \\
\hline In(asset) & 1.02 & 0.00 & 0.99 & 0.00 & 1.02 & 0.00 & 1.09 & 0.00 \\
\hline$(\ln (w))^{2}$ & -0.07 & 0.66 & -0.13 & 0.35 & 0.26 & 0.18 & -0.07 & 0.74 \\
\hline$(\ln (r))^{2}$ & -0.05 & 0.02 & 0.00 & 0.74 & 0.00 & 0.80 & \begin{tabular}{|l|}
-0.01 \\
\end{tabular} & 0.55 \\
\hline$(\ln (k))^{2}$ & 0.01 & 0.71 & 0.05 & 0.04 & -0.02 & 0.48 & -0.02 & 0.62 \\
\hline $\ln (w)^{\star} \ln (r)$ & -0.03 & 0.84 & -0.10 & 0.13 & 0.02 & 0.83 & \begin{tabular}{|l|}
0.02 \\
\end{tabular} & 0.83 \\
\hline $\ln (w)^{\star} \ln (k)$ & -0.03 & 0.80 & 0.25 & 0.00 & -0.27 & 0.00 & -0.09 & \begin{tabular}{|l}
0.37 \\
\end{tabular} \\
\hline $\ln (r)^{\star} \ln (k)$ & 0.13 & 0.04 & -0.13 & 0.00 & -0.03 & 0.66 & -0.09 & 0.05 \\
\hline $\mathrm{H}$-statistics & \multicolumn{2}{|c|}{0.55} & \multicolumn{2}{|c|}{0.91} & \multicolumn{2}{|c|}{0.45} & \multicolumn{2}{|c|}{0.83} \\
\hline Adjusted $\mathrm{R}^{2}$ & \multicolumn{2}{|c|}{0.89} & \multicolumn{2}{|c|}{0.90} & \multicolumn{2}{|c|}{0.89} & \multicolumn{2}{|c|}{0.90} \\
\hline No. of obs. & \multicolumn{2}{|c|}{233} & \multicolumn{2}{|c|}{226} & \multicolumn{2}{|c|}{202} & \multicolumn{2}{|c|}{195} \\
\hline $\mathrm{p}(\mathrm{H}=0)$ & \multicolumn{2}{|c|}{0.00} & \multicolumn{2}{|c|}{0.00} & \multicolumn{2}{|c|}{0.01} & \multicolumn{2}{|c|}{0.00} \\
\hline$p(H=1)$ & \multicolumn{2}{|c|}{0.00} & \multicolumn{2}{|c|}{0.44} & \multicolumn{2}{|c|}{0.00} & \multicolumn{2}{|c|}{0.29} \\
\hline
\end{tabular}

Note: Dummy variables are suppressed. 
As shown in <Table 4>, at $1 \%$ significance level, we reject the hypotheses of "perfect competition" for 2009, 2013, and 2015 while we reject "monopoly" for 2010, 2012, 2013, 2014, 2015 and 2016. In most years since 2009, we can argue that the securities broker-dealer markets are not in "monopoly" nor in "perfect competition." At 5\% level of significance, "monopoly" is rejected except for 2009 while "perfect competition" is rejected except for 2010, 2014, and 2016.

To understand whether the competition in broker-dealer markets becomes intense or loose, we draw the $\mathrm{H}$-statistics over the time.

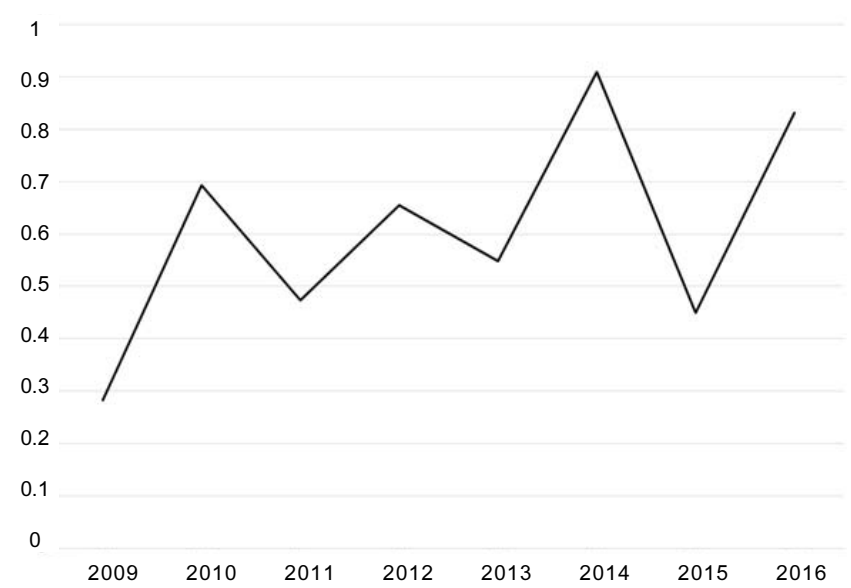

<Figure 1> Trend in H-statistics of securities broker-dealer markets in Korea for FY 2009-2016

$<$ Figure $1>$ visualizes the $\mathrm{H}$-statistics by regression results of $\langle$ Table $4>$. H-statistics tend to incline slightly, that is, the market seems to trend toward being more competitive. However, we do not have sufficient evidence for intensified competition among securities companies. Most of $\mathrm{H}$-statistics are moving between 0.3 and 0.9 and we can vaguely infer that Korean securities market had been in the status of "monopolistic competition" at least.

\section{Conclusions and Discussions}

\subsection{Concluding Remarks}

Using different competition measures, Gwon and Park (2016) show that we can arrive at different conclusions on how much pressure the financial securities companies face over the decade. Traditional $\mathrm{HHI}$ enunciate that monopoly power appears to come back since 2012 while H-statistics and Boone indicator show that competition is prevailing gradually for the same time. Moreover, by $\mathrm{H}$-statistics, they maintain that Korean securities industry is transforming from monopolistic competition to perfect competition except for the global financial crisis.
This paper agrees mainly with Gwon and Park (2016) but it cannot warrant the trend toward higher competition in the markets. Truncating the time with more consistent accounting information and applying more comparable methodology by existing literature than Gwon and Park (2016), we can argue that the competition among securities broker-dealer markets is away from monopoly. The markets seem gradually competitive, but they are still distant from perfect competition either.

In sum, H-statistics of this paper examines the Korea's financial securities broker-dealer markets are in the state of "monopolistic competition." This result is somewhat puzzling when we compare it with banking industries since the securities markets are usually thought to be more competitive than banking industry is. Bikker and Spierdijk (2008) report that Korea's banking sector is so competitive that $\mathrm{H}$-statistics is close to 1 or above for 1994-2001, which flies in the face of common sense.

\subsection{Limitations and Further Research}

Measuring competition using $\mathrm{H}$-statistics challenges the use of traditional measures such as $\mathrm{HHI}$ and $\mathrm{CR}$. But that does not imply new methods are better than old ones. Bikker and Spierdijk (2012) argue that H-statistics in spirit of Panzar and Rosse (1987) seem to be a better measure regarding the government regulation on financial markets. However, recent literature reports the instability of $\mathrm{H}$-statistics when we apply the method to the short period. This kind of problem is identified again in <Table $4>$ and <Figure $1>$ of this paper. Despite of these drawbacks, we might apply this method to somewhat longer time span as shown in <Table 3>. Fundamental instability with $\mathrm{H}$-statistics deserves further attention and alternative methods, presumably better than $\mathrm{H}$-statistics, are discussed recently (Shaffer \& Spierdijk, 2017).

More elaboration on the precision of new measures is required. For example, we can account for the corporate ownership structure of financial groups and multi-product features of an individual company.

Another research agenda is to find a relationship between policy evaluation and the competition measures. The use of competition measure can be tested in the context of regulatory regime. The policy would be evaluated by the measures and the measured would be mended for the policy.

\section{References}

Bain, J. (1956). Barriers to New Competition: Their Character and Consequences In Manufacturing Industries. Cambridge, MA: Harvard University Press.

Baumol, W. J., Panzar, J. C., \& Willig, R. D. (1982). Contestable Markets and the Theory of Industry 
Structure. New York: Harcourt Brace Jovanovich.

Bikker, J., \& Haaf, K. (2002). Competition, concentration and their relationship: An empirical analysis of the banking industry. Journal of Banking \& Finance, 26(11), 2191-2214.

Bikker, J., Shaeffer, S., \& Spierdijk, L. (2012). Assessing competition with the Panzar-Rosse model: The role of scale, costs, and equilibrium. Review of Economics and Statistics, 94(4), 1025-1044.

Bikker, J., \& Spierdijk, L. (2008). How banking competition changed over time. DNB Working Paper No.167 February 2008.

Claessens, S. (2009). Competition in the financial sector: Overview of competition policies. The World Bank Research Observer, 24(1), 83-118.

Claessens, S., \& Laeven, L. (2004). What drives bank competition? Some international evidence. Journal of Money, Credit, and Banking, 36(3), 563-583.

De Bandt, O., \& Davis, E. P. (2000). Competition, contestability and market structure in European banking sectors on the eve of EMU. Journal of Banking and Finance, 24(6), 1045-1066.

Degryse, H., Kim, M., \& Ongena, S. (2009). Microeconometrics of Banking: Methods, Applications, and Results. NY: Oxford University Press.

Gwon, J. H., \& Park, Y. R. (2016). Contestability of securities industry in Korea and potential for structural change. Korea Capital Market Institute, Research Paper 16-02.

Humairoh, S., \& Usman, H. (2016). Competition of Islamic bank in Indonesia. Journal of Distribution Science, 14(6), 39-44. doi: 10.15722/jds.14.6.201606.39

Lee, S. H., Shin, B. S., Lee, J. H., \& Park, S. H. (2008). Analysis and implication of changes in securities markets competition. Korea Securities Research Institute, Research Report 08-05.

Nathan, A., \& Neave, H. (1989). Competition and contestability in Canada's financial system: Empirical results. Canadian Journal of Economics, 22(3), 567-594.

Panzar, J. C., \& Rosse, J. N. (1987). Testing for 'monopoly' equilibrium. Journal of Industrial Economics, 35(4), 443-456.

Sohn, K. W., \& Liu, W. (2015). The price of risk in the Korean stock distribution market after the global financial crisis. Journal of Distribution Science, 13(5), 71-82. doi: 10.15722/jds.13.5.201505.71

Shaeffer, S., \& Spierdijk, L. (2017). Market power: Competition among measures. In J. A. Bikker, \& L. Spierdijk, Handbook of competition in banking and finance (pp.11-26), Cheltenham, UK: Edward Elgar Publishing.

Tsutsui, Y., \& Kamesaka, A. (2005). Degree of competition in the Japanese securities industry. Journal of Economics and Business, 57(4), 360-374.

U.S. Department of Justice and the Federal Trade Commission (2010). Horizontal merger guidelines (2010.9.19.). 